\title{
Synchronous, Multiple Primary Lung Cancers: A Report of Three Cases
}

\author{
Baykal Tülek ${ }^{1}$, Füsun Baba², Esra Innan ${ }^{1}$, Fikret Kanat ${ }^{1}$, Mecit Süerdem ${ }^{1}$ \\ ${ }^{1}$ Department of Chest Diseases, Selçuk University Faculty of Medicine, Konya \\ ${ }^{2}$ Department of Pathology, Selçuk University Faculty of Medicine, Konya
}

\begin{abstract}
Multiple primary lung cancers (MPLC) are named synchronous if determined simultaneously with the index tumor, and metachronous if the second tumor is diagnosed with an accepted time after the first tumor. It is important for both the rate of survival and treatment alternatives to differentiate synchronous MPLCs from the metastases of the primary lung tumors, and also from the multiple pulmonary metastases of the extra pulmonary tumors. In this study, clinical characteristics, diagnosis and treatment processes of three synchronous MPLC cases diagnosed in our department were assessed.
\end{abstract}

Keywords: Lung cancer, neoplasm metastases, synchronous multiple primary neoplasms

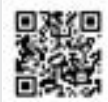

Received Date: 20.07.2012 Accepted Date: 03.11.2012

Address for correspondence Baykal Tülek, Department of Chest Diseases, Selçuk University Faculty of Medicine, Konya, Turkey E-mail: baykaltulek@yahoo.com cc) (9) $\begin{aligned} & \text { This work is licensed under a Creative } \\ & \text { Commons Attribution-NonCommercia }\end{aligned}$ 4.0 International License.

DOI: 10.5152/ejp.2014.37929

- Available online at www.eurasianjpulmonol.com

\section{INTRODUCTION}

Multiple primary lung cancers (MPLC) are divided into two categories, namely synchronous and metachronous. If tumors are determined simultaneously, they are called synchronous, but if the second tumor is determined after a certain time from the detection of the initial lesion, it is called metachronous. In recent years, in parallel with the usage of multislice computed tomography (CT) and positron emission tomography with 18F-fluorodeoxyglucose (FDG-PET), the incidence of synchronous MPCL has increased (1-3). It is highly important to distinguish synchronous MPLS from both lung metastases of primary tumors and multiple lung metastases of non-lung tumors.

In this study, clinical features, diagnosis, and treatment periods of three synchronous MPCL cases diagnosed in our clinic were examined.

\section{CASE PRESENTATIONS}

\section{Case 1}

A 68-year-old male patient presented with the complaint of shortness of breath, fatigue, and weight loss. His physical examination findings were normal. His chest $x$-ray revealed bilateral hilar fullness and properly limited opacity in the right middle zone. A mass surrounding the intermediate bronchial wall in the right lobe, a $4 \mathrm{~cm}$ lobulated lesion at the apical segment of the right lower lobe, a $2.5 \mathrm{~cm}$ lobulated lesion in the right middle lobe, a soft tissue appearance, and mediastinal hilar lymph nodes were detected on thorax CT (Figure 1a, b). The patient's bronchoscopy revealed tumor lesions in the right intermediate bronchial wall and at the entry of the left upper lobe bronchus. Histopathological examination of the biopsy taken from the intermediate bronchus revealed the presence of small-cell carcinoma, and the diagnosis of squamous cell carcinoma was also established with the examination of the biopsy taken from the lesion in the left upper lobe (Figure 2).

On the cranial magnetic resonance imaging (MRI) performed for the purpose of staging, a $2 \times 2 \mathrm{~cm}$ mass consistent with metastasis was observed in the left frontal lobe. Common liver, muscle, and bone metastases were detected on FDG-PET. The maximum standardized uptake value $\left(\mathrm{SUV}_{\max }\right)$ was 7.65 for 
the mass around the right intermediate bronchus and 6.81 for the mass in the left lung (Figure $1 \mathrm{~b}$ ). The patient for whom radiotherapy for brain metastasis and zoledronic acid treatment for bone metastasis were initiated was followed up with palliative support treatment because of poor performance scores.

\section{Case 2}

A 56-year-old male patient who presented with the complaints of shortness of breath, headache, nausea, and vomiting was examined. His chest $x$-ray revealed irregular-margined opacities in the left upper zone. Thus, contrast-enhanced thoracic CT was performed and a $7 \times 5 \mathrm{~cm}, 5 \mathrm{~cm}$ irregular-margined lobulated mass in the apicoposterior segment of the left upper lung lobe and a solid, linear and nodular lesion which did not show certain mass formation were observed (Figure 3a). Cranial MRI revealed metastatic lesions of approximately $3 \mathrm{~cm}$ in diameter in the left temporal and right frontal lobes (Figure $3 b$ ). The patient, who was consulted with brain surgery, underwent urgent metastasectomy and postoperative cranial radiotherapy was administered. After the operation, the general condition of the patient improved and bronchoscopy revealed a mucosal irregularity at the entry of the upper right lobe and a tumoral lesion obstructing the apicoposterior segment of the left upper lobe completely. From the mucous biopsy samples, poorly differentiated squamous cell carcinoma and large cell neuroendocrine carcinoma were diagnosed. Besides, the biopsy sample taken from the patient during the operation performed for metastatic brain tumor was found to be consistent with large cell neuroendocrine carcinoma. Chemotherapy was initiated and the patient was followed up.

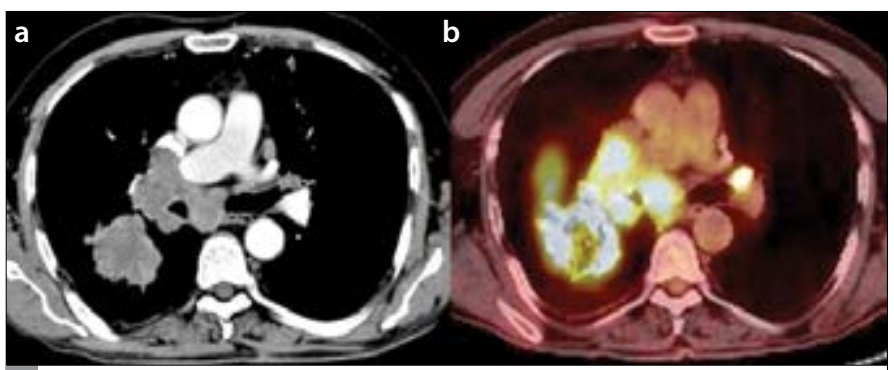

Figure 1. a, b. Thoracic CT revealed mass lesions in the right hilar region, right lower lobe, and left upper lobe bronchus (a). FDG-PET revealed increase in metabolic activity in mass lesions observed on CT (b)

\section{Case 3}

The thoracic CT of the 74-year-old male patient, who presented with the complaint of shortness of breath, revealed a lobulated mass lesion, the largest axial dimension of which was measured to be about $25 \times 45 \mathrm{~mm}$, in the right hilar region, an approximately $25 \times 40 \mathrm{~mm}$ sized mass lesion associated with the pleura in the upper lobe of the right lung, and a mass lesion in the bilateral adrenales (Figure $4 a, b$ ). Because the result of the transthoracic biopsy performed for the peripheral mass in the upper lobe of the right lung was consistent with adenocarcinoma, the patient was referred to our clinic. In the bronchoscopy performed at our clinic, a mucosal irregularity, which was $1 \mathrm{~cm}$ away from the carina in the anterior wall of the right main bronchus, extending to the upper lobe bronchus and blocking the anterior segment entry, was observed. Moreover, mucosal irregularity, which obstructed the lumen at the rate of $40-50 \%$, was seen in the middle lobe entry. Mucosa biopsy was taken separately from the middle and upper lobes and bronchoalveolar lavage was taken from the upper lobe. In the pathological examination, mucosa samples taken from the upper right and middle lobes were consistent with small-cell lung carcinoma. On FDG-PET, the SUV $_{\text {max }}$ of the irregular-margined, $23 \times 36 \mathrm{~mm}$ sized mass lesion in the right lung anterior segment was 16 and of the right hilar conglomerate lymph node was 16.1. In addition, increased metabolic activity involvement was observed in the right lower paratracheal and bilateral adrenal glands (Figure 4c, d). On cranial MR, no metastasis was detected. The patient whose general condition was poor and hypoxemic was followed up with supportive treatment after prophylactic brain radiotherapy.

\section{DISCUSSION}

The incidence of synchronous MPLC is between $0.2 \%$ and $20 \%$ and an increase is observed in the frequency of these tumors with the

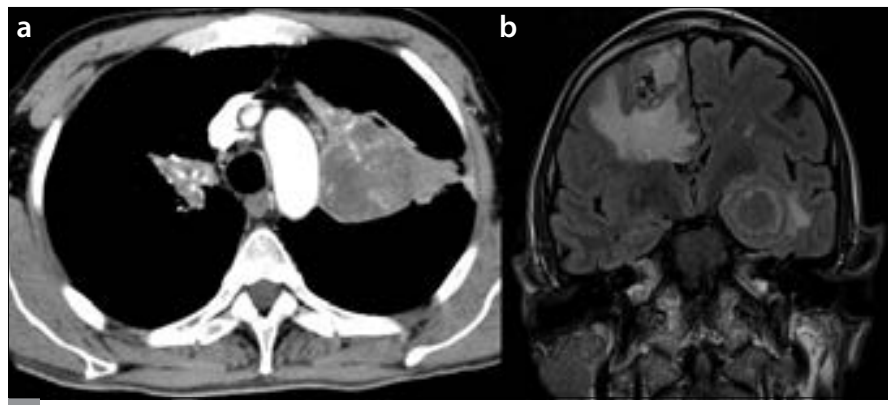

Figure 3. a, b. Thoracic CT revealed a mass lesion in the left upper lobe and right parahilar nodular lesion (a). Brain MR revealed metastases in the left temporal and right frontal lobes (b)

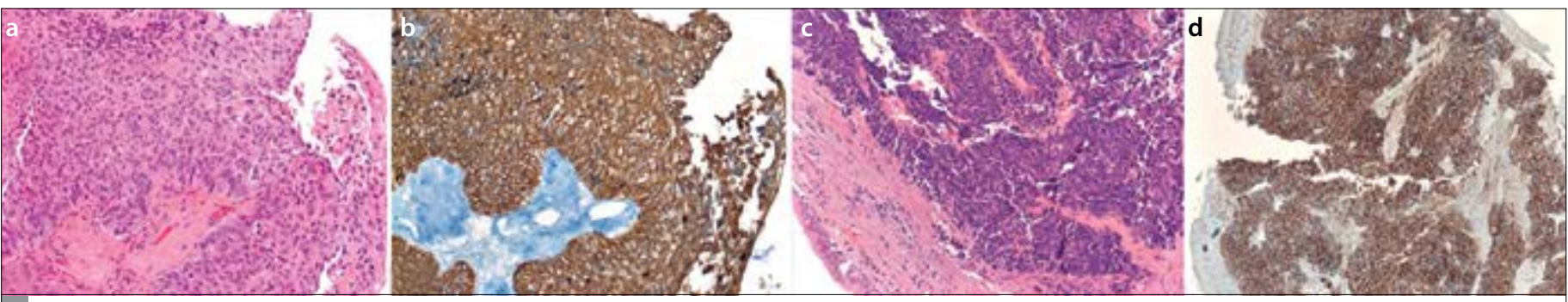

Figure 2. a-d. Squamous cell carcinoma (20X, HE): tumoral tissue consisting of atypical squamous cells with hyperchromatic pleomorphic nucleus, large eosinophilic cytoplasm, and apparent intracellular desmosomes (a). (20X, DAB) Tumoral tissue showing positive immunoexpression with cytoceratine $5 / 6$ (b). Small-cell lung cancer (20X, HE): tumoral tissue consisting of cells with hyperchromatic oval nucleus, with infiltration under bronchial mucosa, intense crush artifact, and unclear cytoplasmic borders (c). (10X, DAB) tumoral cells showing positive immunoexpression with CD56 (d) 


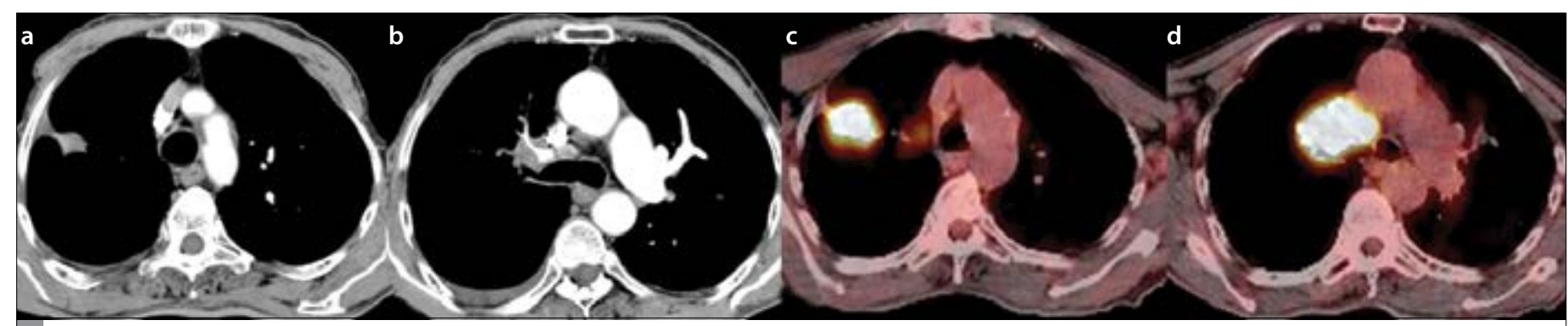

Figure 4. a-d. Thoracic CT revealed a nodule associated with the pleura in the right upper lobe (a) and a mass surrounding the right upper lobe bronchus (b). FDG-PET revealed increase metabolic activity in lesions observed on CT (c, d) (Note: The time interval between CT and FDG-PET examinations is 1 month)

use of modern imaging methods (1-3). It was found that in synchronous MPLC, the histopathological diagnosis was epidermoid cancer in $60 \%$ of the patients and approximately $60 \%$ of them had the same histological type of tumor (4). Especially, the coexistence of smallcell and non-small-cell cancers is rare (5). All the cases in our study had different histological types of tumors. The histopathological results of our patients were small-cell cancer-epidermoid cancer, large cell neuroendocrine cancer-epidermoid cancer, and small-cell cancer-adeno cancer, respectively. Although two of three patients in our study had coexistence of small-cell and non-small-cell lung cancer, the other patient had large cell cancer with neuroendocrine origin.

In $16-28 \%$ of patients with lung cancer, there may be other nodules in the lungs. In such a case, it creates confusion during the process of diagnosis to determine whether these nodules are primary tumor metastasis, multiple primary lung cancer, or benign lesions (6). In a previous study, it was noted that $96 \%$ of separate nodules smaller than $10 \mathrm{~mm}$ were benign; thus, the option of surgical treatment should not be ignored (6). Yuan et al. (7) found that the possibility of malignancy was high if primary tumors and nodules coexisted in the same lobe. In the same study, it was detected that it was more possible for synchronous lung tumors to be in the same hemithorax but a different lobe or in the opposite hemithorax. In two of three cases examined in our study, lesions were located in the opposite lung, which was consistent with this result, and in one case, lesions were in the same lobe.

In cases with lung cancer, when another focus is the matter of discussion, it is easy to establish the diagnosis of synchronous MPLC if the histopathological diagnoses of two regions are different. When the same histopathological diagnosis is discussed in different focuses, molecular genetic studies may be required (8), but the use of these examinations in routine clinical practice is highly limited. Then, it is stated that the absence of mediastinal lymph nodes and remote metastases is required for the diagnosis of synchronous MPLC (4). In all of our three cases, there were different histopathological diagnoses; thus, there was no need for further examination.

Dijkman et al. (9) suggested that SUV results obtained using FDG-PET could be used in the differentiation of metastasis and synchronous MPLC. In this retrospective study, it was detected that the $\triangle$ SUV results were greater in primary synchronous tumor cases (8.58 \pm 5.24$)$ than in the metastatic group $(4.00 \pm 4.22)$. In two cases in our study, FDG-PET examination was performed, but the $\triangle$ SUV results $(0.84$ and 0.13 , respectively) were lower compared with the results in the study of Dijkman et al. (9).
In synchronous MPLC cases, survival is quite variable. It was revealed that the 5 -year survival rate ranged from $0 \%$ to $79 \%$ in cases in which both tumors were classified as stage 1 (1, 10-12). Van Rens et al. (13) reported that the 5-year survival rates of synchronous MPLC patients were worse than those of patients with one primary cancer in similar stages ( $19 \%$ vs. $41 \%$, respectively). In the same study, the most advanced stage among the synchronous MPLC patients was the best predictor for survival. Because survival rate is lower in synchronous MPLC patients than in patients with similar stages, it is recommended that scanning tests, including remote organ metastasis examination and mediastinoscopy, be performed with additional care (4).

The differentiation of synchronous MPLC and lung metastasis is significant. It has been revealed that the long-term survival rate in synchronous MPLC patients who have undergone resection is higher than that in stage 3B and stage 4 patients. Therefore, surgical resection, especially aggressive surgical approaches, is thought to be an important treatment option for long-term survival in these patients (14). Because all of the patients in our study had metastatic cancer, it was not possible to consider the surgical treatment option. Chemotherapy was administered to two of the patients and one patient received palliative support treatment. The patients are still being followed up in our clinic.

\section{CONCLUSION}

For the patients who are followed up because of the diagnosis of lung cancer and who have more than one lesion, the possibility of synchronous MPLC should be considered and histopathological sampling should be performed for each lesion separately. Although the survival rates in these patients are worse than those in patients with primary lung cancer at the same stage, aggressive surgery options should be considered for suitable patients.

Informed Consent: Due to the retrospective design of the study, informed consent was not taken.

Peer-review: Externally peer-reviewed.

Author contributions: Concept - B.T.; Design - B.T.; Supervision - B.T.; Resource - B.T.; Materials - B.T., F.B.; Data Collection and/or Processing - B.T., F.B., E.I.; Analysis and/or Interpretation - B.T., F.K.; Literature Search - B.T.; Writing - B.T.; Critical Reviews - B.T., F.K. M.S.

Conflict of Interest: No conflict of interest was declared by the authors.

Financial Disclosure: The authors declared that this study has received no financial support. 


\section{REFERENCES}

1. Ferguson MK, DeMeester TR, DesLauriers J, Little AG, Piraux M, Golomb $\mathrm{H}$. Diagnosis and management of synchronous lung cancers. J Thorac Cardiovasc Surg 1985; 89: 378-85.

2. Wu SC, Lin ZQ, Xu CW, Koo KS, Huang OL, Xie DQ. Multiple primary lung cancers. Chest 1987; 92: 892-6. [CrossRef]

3. Carey FA, Donnelly SC, Walker WS, Cameron EW, Lamb D. Synchronous primary lung cancers: prevalence in surgical material and clinical implications. Thorax 1993; 48: 344-6. [CrossRef]

4. Detterbeck FC, Jones DR, Kernstine KH, Naunheim KS; American College of Physicians. Lung cancer. Special treatment issues. Chest 2003; 123 : 244S-58S. [CrossRef]

5. Hiraki A, Ueoka H, Yoshino T, Chikamori K, Onishi K, Kiura K, et al. Synchronous primary lung cancer presenting with small cell carcinoma and non-small cell carcinoma and non-small cell carcinoma: diagnosis and treatment. Oncol Rep 1999; 6: 75-80.

6. Kim YH, Lee KS, Primack SL, Kim H, Kwon OJ, Kim TS, et al. Small pulmonary nodules on $\mathrm{CT}$ accompanying surgically resectable lung cancer: likelihood of malignancy. J Thorac Imaging 2002; 17: 40-6. [CrossRef]

7. Yuan $\mathrm{Y}$, Matsumoto T, Hiyama A, Miura G, Tanaka N, Emoto T, et al. The probability of malignancy in small pulmonary nodules coexisting with potentially operable lung cancer detected by CT. Eur Radiol 2003; 13 : 2447-53. [CrossRef]

8. Arai J, Tsuchiya T, Oikawa M, Mochinaga K, Hayashi T, Yoshiura K, et al. Clinical and molecular analysis of synchronous double lung cancers. Lung Cancer 2012; 77: 281-7. [CrossRef]

9. Dijkman BG, Schuurbiers OC, Vriens D, Looijen-Salamon M, Bussink J, Timmer-Bonte JN, et al. The role of (18)F-FDG PET in the differentiation between lung metastases and synchronous second primary lung tumours. Eur J Nucl Med Mol Imaging 2010; 37: 2037-47. [CrossRef]

10. Rosengart TK, Martini N, Ghosn P, Burt M. Multiple primary lung carcinomas: prognosis and treatment. Ann Thorac Surg 1991; 52: 773-8. [CrossRef]

11. Okada M, Tsubota N, Yoshimura M, Miyamoto Y. Operative approach for multiple primary lung carcinomas. J Thorac Cardiovasc Surg 1998; 115: 836-40. [CrossRef]

12. Antakli T, Schaefer RF, Rutherford JE, Read RC. Second primary lung cancer. Ann Thorac Surg 1995; 59: 863-6. [CrossRef]

13. van Rens MT, Zanen P, Brutel de La Riviere A, Elbers HR, van Swieten HA van Den Bosch JM. Survival in synchronous vs. single lung cancer: upstaging better reflects prognosis. Chest 2000; 118: 952-8. [CrossRef]

14. Jung EJ, Lee JH, Jeon K, Koh WJ, Suh GY, Chung MP, et al. Treatment outcomes for patients with synchronous multiple primary non-small cell lung cancer. Lung Cancer 2011; 73: 237-42. [CrossRef] 